\title{
Under-Ventilated Wall Fire Behaviour during the Post- Flashover Period
}

\author{
J.M. Most ${ }^{\dagger}$ and J.B. Saulnier \\ Institut P', CNRS, ENSMA, Université de Poitiers, ENSMA, 1, avenue Clément Ader, BP 40109 \\ F - 86961 FUTUROSCOPE Cedex \\ $\dagger$ Corresponding Author Email: jean-michel.most@lcd.ensma.fr
}

(Received July 16, 2010; accepted March 13, 2011)

\begin{abstract}
This work is aimed the evolution of the behaviour of a strongly contained wall fire in an enclosure during the postflashover period. It has characterised the fire intensity decay up to extinction of a wall fire by lack of oxygen and the effects of a sudden door opening on the formation of an air gravity wave capable to bring the backdraft phenomenon. To better understand these two sequential fire scenarios, the study was divided into two complementary parts performed in the same laboratory scale experimental setup. The first part consists to stabilise a steady wall fire at the rear of the compartment and to follow its evolution when a door closes the aperture leaving only a thin slot opened to limit the air entering. It has been observed the formation of a ghosting flame moving through the compartment before dying at the aperture. By supposing the continuation of the fuel solid pyrolysis after flame extinction due to the radiation of the hot environment, fuel vapours continue to fill the compartment. The second part will study the effects of a reopening of the door. It has been observed and characterised the formation and the propagation of a gravity wave through the enclosure. This is representative of the development of the first stage of the backdraft. Tests are performed to measure the aerodynamic properties of the flow behaviour.
\end{abstract}

Keywords: Fire dynamics, Compartment fire, Ghosting flame, Backdraft, Flashover.

\section{INTRODUCTION}

The term "compartment fire" is used to describe a fire, which is confined within a room or a similar enclosure within a building. Drysdale (1999) defines different stages, illustrated in Fig. 1, corresponding to the rate of burning which is controlled by the rate of ventilation or the available fuel load:

- The growth or pre-flashover stage in which the average temperature is low and the fire is localized in the vicinity of its origin. During its initial phase, the fire grows as long as it is fuelcontrolled;

- The fully developed or post-flashover fire, during which combustible items in the compartment, is involved (rapid spread from the area of localized burning to all combustible surfaces within the room). Flames appear to fill the entire volume;

- A regime, represented by the broken line, which reports depletion of fuel before flashover has been achieved;

- The decay period formally identified as that stage of the fire after the average temperature has fallen to $80 \%$ of its peak value. At this stage, according either to a lack of fuel or oxygen, extinction appears;
- On the original Drysdale scheme (Fig. 1), another phenomenon is reported, which appears sometime after extinction. If fuel is still available in the compartment after extinction (extinction for a ventilated-controlled regime), thermal radiation of the walls and hot gases in the enclosure maintain the pyrolysis of the combustible load. If an opening occurs (window breaking or door opening by fire-fighters), fresh air is carried into the room by buoyancy forces, mixed with full rich hot gases that can induce reactants ignition and the propagation of a dangerous fire wave through the room.

\subsection{Post Flashover Wall Fire Behaviour and Extinction}

Many studies have been conducted on the fire behavior in compartment, several reviews were proposed, for example those of Babrauskas et al. (1992), and Karlsson et al. (2000). They concern mainly the fire growth of small sources, the toxic products and smoke generation, and the characteristic time for a potential transition to flashover. The development of such a room fire is strongly linked to the combustion parameters, the location of the available fuel material, the air mass flow rate feeding the combustion, and the thermal properties 
of the environment. Moreover, the geometry and the scale of the compartment, and the air supply characteristics can play an important role in the fire growth or size (Thomas 1980), modifying the conditions leading to flashover. Quintiere et al. (1978) give similar conclusions as Gross et al. (1964) study for a PMMA slab. They show that, on the one hand, for small widths of the opening, the fuel pyrolysis rate increases with the air ventilation as long as mass oxygen fraction is sufficient; and, on the other hand, for larger openings, the mass loss depends on the fuel surface and on the thermal radiation, independently of oxygen excess. These effects of the fire air supply are quantified by Kawagoe (1958) through the ventilation factor $\mathrm{F}_{\mathrm{v}}$ that takes into account the surface $\mathrm{A}_{0}$ and the height $\mathrm{H}_{0}$ of the opening $\left(F_{v}=A_{0} H_{0}^{1 / 2}\right)$. These results will underline the great influence of the available air entrainment on the fire behaviour in extreme condition ventilation regimes.

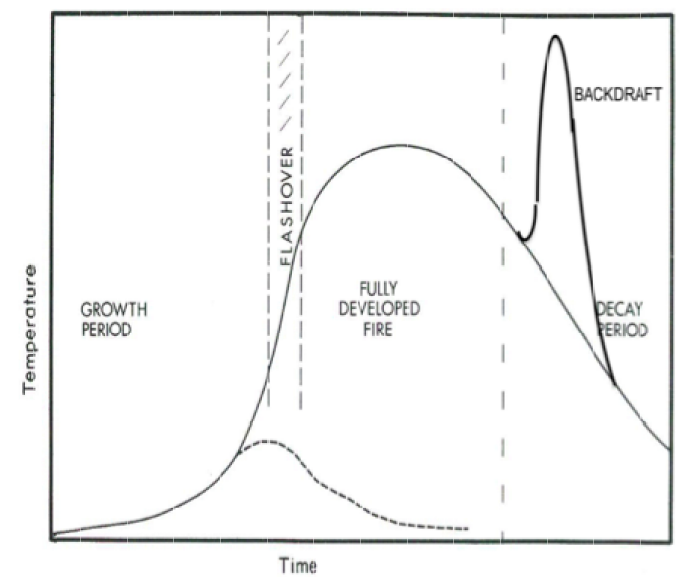

Fig. 1. The course of a compartment fire expressed as an average gas temperature as a function of time (from Drysdale 1999)

During the fire growth period, the air supply is consumed and can become insufficient to completely feed the flame that leads to an under ventilated fire. This scenario corresponds to a partial or complete obstruction of the room opening (for example: pipe filter obstruction by smoke particles). In these conditions, Sugawa et al. (1989) have observed the formation of a blue unsooty flame over a methanol pool fire surface located within a $2 \mathrm{~m}$ width, $0.6 \mathrm{~m}$ height and $3 \mathrm{~m}$ long enclosure. Later, Morehart et al. (1992) have conducted experiments on flammability limit in confined environment. A lifted flame has been observed over the pyrolysis surface and referred as a ghosting flame. This flame behaviour, similar to the ghosting flame obtained by Sugawa's (1989), has also been observed by Audouin et al. (1997) during a full-scale test where a liquid hydrocarbon pool fire was ignited on the floor of an enclosure of $3.75 \mathrm{~m}$ width, $2.5 \mathrm{~m}$ height and $10 \mathrm{~m}$ length, with a $0.64 \mathrm{~m} 2$ opening. A thick smoke has been produced and the temperature at the ceiling level has reached $760^{\circ} \mathrm{C}$. The overpressure obtained in the room has induced the exhaust of the combustion products through the opening, reducing the fresh air entry. Five minutes after ignition, the combustion intensity has decreased drastically, the originally yellow flame (soot radiation) has turned to blade blue, and a ghosting flame has moved to the aperture. The first part of the present work will identify the potential transition between of a fully developed wall fire to a ghosting flame. Pearson (2007) made similar observations in a laboratory scale enclosure. The fuel source was placed in the under-ventilated zone of a compartment; the flame has left the fuel surface to be stabilised at the interface between air and fuel rich upper layers vitiated by combustion producys. The conditions have characteristics similar to a ghosting flame.

The first part of this experimental work will aim to the characterisation of an under-ventilated wall fire. The fire evolution is followed under conditions allowing the development of a ghosting flame which leaves the simulated pyrolysis surface before extinction through a lack of oxygen and move to a small aperture. The results will allow interpreting the involved phenomena and proposing hypothesis on the flame structure.

\subsection{Backdraft Phenomenon}

The second study corresponds to the next stage of the previous post-flashover scenario: a door opening induces a fluid motion of cold heavy air in the hot enclosure by buoyancy effect. It was been observed by Chitty (1994), Gojkovic (2001), Bengtsson (2000), Fleischmann (1999), that transport and mixing between fluids with different densities are thus essential initial factors for the probability of occurrence and intensity of the backdraft phenomena. The mixture can then become flammable (equivalence ratio within the flammability limit of the combustible vapours), and, in case of ignition by contact with a hot surface, trigger a backdraft. This type of combustion in a variable equivalence ratio environment is extremely hazardous and has killed many fire-fighters in the past years (Fahy 2006).

Previous studies dedicated to backdraft "Weng (2002), Fleischmann (1993), Gottuk (1999), Guigay (2006) have identified the concentrations of the different gases prior to opening, and especially the unburnt combustible gases, as being an essential parameter in the probability of occurrence and the intensity of a backdraft. However, there has been very few description of the gas dynamics and the mixing occurring during the period between opening and ignition, and this is clearly a gap in the identification of the ignition conditions and the combustion propagation.

The first goal of this second part of this study, performed in inert genvironment, is to describe the resulting flow, in order to get a better understanding of the influence and the behavior of gravity waves. These gravity waves control the transport of cold and dense inflowing air, and its mixing with hot gases inside the compartment. The results should fill this gap in the knowledge of backdraft, by satisfying the following main objectives:

- To experimentally validate the three phases flow theory described in the bibliography from experimental original results on the 
average and turbulent flow velocity field Eliasson (2008), Guigay (2008);

- To identify and analyse, from PIV measurements, the turbulent structures observed on turbulence and stratified flows studies (Pedersen 1986). Thus, classical theories, based on a hydraulic approach of zone models and translatory wave theory can be adapted to the backdraft configuration;

- To evaluate the validity of turbulent flow models in numerical codes and to determine the interfacial shear stress between the inflow and outflow layers at the opening of the compartment. Thus, behavior laws could be suggested;

- To obtain a quantitative description of the flow, which will be used to calibrate and validate a numerical modelling of the backdraft phenomenon.

\section{PART 1: EXPERIMENTAL \\ CHARACTERISATION OF THE GHOSTING FLAME FOLLOWING THE POST- Flashover PERIOD}

The experimental apparatus is presented on Fig. 2. The dimensions of the enclosure which will be used for the two complementary studies are $0,62 \mathrm{~m}$ in depth, $0,84 \mathrm{~m}$ in height and $0,41 \mathrm{~m}$ in width. Monitored door is available to partly close the aperture to modify the air ventilation.

\subsection{Experimental Setup, Working Parameters and Diagnostics Methods}

On Fig. 2, the fire source is composed by water-cooled $\left(65^{\circ} \mathrm{C}\right)$ porous flat burner $\left(0.4 \times 0.5 \mathrm{~m}^{2}\right)$ located at the rear of the compartment. A gaseous hydrocarbon (propane) is injected through this burner to partly simulate the degradation of a solid fuel material. Consequently, this operating system allows dissociating the fuel mass flow rate (fire input power) from the heat feedback from the flame. This allows the stabilisation and the characterisation a steady combustion. Various additional equipments (insulated walls, soffit, moving door or electrical heater) can be installed on this laboratory scale box to study several confined fires. The gas mass flow rates are controlled by mass flow meters. On one side of the enclosure, a window allows the visualisation of the flame and optical measurements.

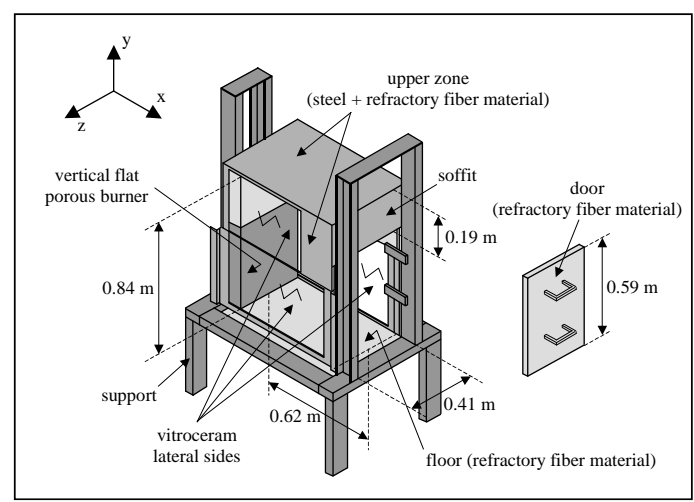

Fig. 2. Experimental setup for ghosting flame study
The aim of the study is recalled, it consists to identify the combustion behaviour when a confined wall fire becomes under-ventilated (Bertin 2002). Four values of the heat release rate $\dot{Q}$ are studied: $18,27,36$ and 45 $\mathrm{kW}$, corresponding to a Grashof number close to $10^{11}$ that is representative of buoyancy driven flow. After the wall fire stabilisation, an adiabatic door is installed at the aperture to reduce the fire ventilation leaving only a narrow slot of $0.41 \times 0.06 \mathrm{~m}^{2}$ between the top of the door $(0,59 \mathrm{~m}$ in height and $0,41 \mathrm{~m}$ in width) and the bottom of the soffit (ventilation factor $\mathrm{F}_{\mathrm{v}}=6.10^{-3}$ ).

The diagnostics methods we used were classical. Temperature evolution in the enclosure was measured by five wire-type $\mathrm{K}$ thermocouple trees, the total heat flux (convective and radiative components) from the flame was obtained by Medtherm radiometers installed on the floor, the spontaneous flame emission was visualised by intensified video camera (shape, colour and motion of flame structures). Two sensors of each type are separated to determine the velocity displacement of the flame. Complementary measurements, not presented in this work, were performed to determine the mean volumetric concentration of characteristic chemical species $\left(\mathrm{O}_{2}\right.$ and $\mathrm{CO}_{2}$ ).

\subsection{Main Results}

Without the door, a wall fire is stabilised along the porous burner (Figs. 3a and 3b). The temperature of the upper layer trapped by the soffit increases with $\dot{Q}$, up to $900^{\circ} \mathrm{C}$. For high $\dot{Q}$ values, the flame interacts with the upper unventilated hot zone and the flame fills practically the whole enclosure (simulation of the postflashover period).

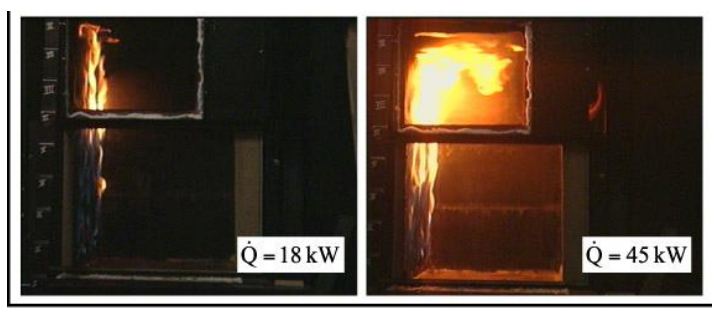

Fig. 3. Ventilated simulated wall fire. Injected gaseous fuel propane mass flow rate corresponding to:

(a) left $\dot{Q}=18 \mathrm{~kW}$; (b) right $\dot{Q}=45 \mathrm{~kW}$.

After door closing is preserved, the pressure increases in the enclosure avoiding air entry through the slim slot. The flame becomes under-ventilated and an exotic behaviour is observed (Fig. 4), the flame emission decreases rapidly in intensity and the yellow soot radiation becomes imperceptible. A weak luminous blue vertical flame (hydrocarbon radical emission) is observed, a flame sheet, still presenting a blue and vertical leg topped by a luminous plume, leaves the burner surface and travels at low velocity to the aperture (around $0.09 \mathrm{~cm} / \mathrm{s}$ determined by video and by the thermocouples or radiometers peaks during the flame passing). These behaviours seem to look like the Sugawa (1989) or Audouin (1997) phenomenon, which was referred as ghosting flame. No convective motion seems to affect the flame sheet (no gravity wave 
formation), which stays in live up to the aperture, a reignition is sometimes observed at the aperture when fresh air flows rapidly into the compartment and ignites a small part of the residual fuel with the oxygen quantities. Temperature measurements through the flame sheet show an increase of temperature in height to reach a maximum of $900^{\circ} \mathrm{C}$ at the top during the flame passing before to fall back at the quasi-initial level at the door closing. Some prematurely extinctions are observed as soon as the flame "foot" leaves the floor surface.
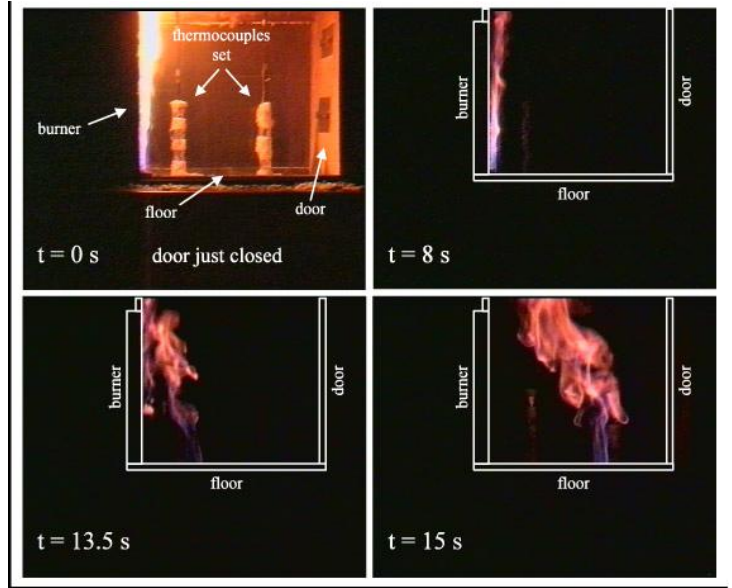

Fig. 4. Ghosting flame visualisation

This phenomenon reproduces the observation of Morehard (1992) on a lifted flame over a pool fire. A diffusion flame structure seems more credible than premixed flame propagation. Figure 5 represents the presumed scheme for the supposed combustion mechanism. The flame is stabilised by a triple flame at the floor level where the reactants are premixed (blue flame) before reacting in their diffusion zone.

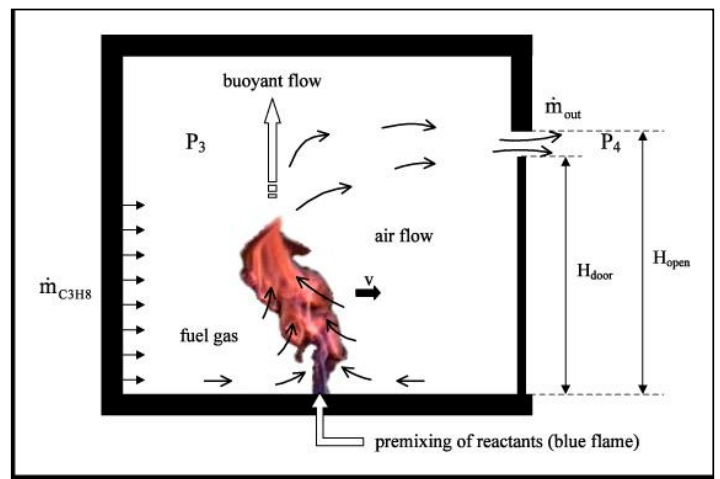

Fig. 5. Ghosting flame mechanism

The buoyant forces create an ascendant motion, which entrains the reactants in a diffusion mechanism; when the flame reaches the hot zone, the buoyant forces vanish and the thermal plume is diluted and soot is produced. To interpret the flame anchoring on the floor, some tests were performed with methane. In these conditions, no ghosting flame was observed: methane, being lighter than air, the reactants are stratified and cannot be premixed at the floor level to stabilise the triple ghosting flame, which has be obtained only with heavy fuel gases such as propane crawling on the floor.

\subsection{Discussion and Perspectives}

A ghosting flame, interpreted as a diffusion flame stabilised at the ground level by a triple flame, is observed in the above fire conditions. The results show a low probability of re-ignition and flame feed back inside the fuel rich enclosure: despite the enclosure cooling, air entrance through the slot is not sufficient to form an efficient fuel/air mixture inside the enclosure inside the flammability limits of propane. To conclude, the backdraft phenomenon cannot be self-induced by a ghosting flame. Nevertheless, a fast door opening can produce an air gravity wave and lead to the ad-hoc conditions for the triggering of backdraft, it will be the objective of the following fire scenario.

\section{Part 2: DeVelopment of a Gravity WAVE LEADING TO BACKDRAFT}

The goal of this second part of this work is aimed to a better understanding of the mixing mechanisms and the formation of vortex structures at the interface between the inflow and outflow with different temperatures (thermal instabilities), and its consequences on the initial conditions of the backdraft phenomenon.

\subsection{Experimental Setup, Working Parameters and Diagnostics Methods}

Now, the test was limited to the investigation of the formation of a gravity wave into a hot air enclosure. The previous setup is only slightly modified (Fig. 6). The post-flashover period has been partly thermally simulated by heating the compartment by $3.2 \mathrm{~kW}$ electric resistance to control mean temperature differences $\Delta T=T_{b}-T_{c}$ between the enclosure and ambient air measured by K-type thermocouples. A sliding plate $(0.16 \mathrm{~m}$ high and covering the entire width of the front wall and controlled by a motorized opening system, was designed to minimize the aerodynamic perturbations during the 0.8 seconds of the opening (ventilation factor $\mathrm{F}_{\mathrm{v}}=25.610^{-3}$ ). These plates are positioned allowing opening either on the lower part of the enclosure, or on the central part (step effect): at the bottom and in the center of the front side of the enclosure, configurations which will be referred to as bottom and middle opening configurations respectively. The position of the opening and the $\Delta \mathrm{T}$ value $(\Delta \mathrm{T}=30$, $55,80,105,130,155,180,220^{\circ} \mathrm{C}$ ) are the main parameters of the study. Before the test, air temperature in the compartment is homogenised by a fan. The displacement of the gravity wave entering the enclosure is characterised by a Time Resolved PIV system (TRPIV).

The used Time Resolved PIV system includes a two cavity Nd-YAG Laser, 200 pairs of images/s. The optical system allows the treatment of a $15 \times 15 \mathrm{~cm}^{2}$ area, which is smaller than the total zone of interest, the displacement in the compartment covers a length: 0.8 meters with a time order of magnitude of 4 seconds. Therefore, an original system is developed and monitored. The PIV camera is automatically displaced during the experiment to follow the wave motion during its propagation inside the enclosure. This technique couples a good temporal resolution of the gravity wave 
(periodicity of passage of the vortices), and a precise determination of its characteristics (size, shape,...), which cannot be determined using a traditional PIV. Acquisition for both tomography and PIV is triggered simultaneously with the hatch opening.

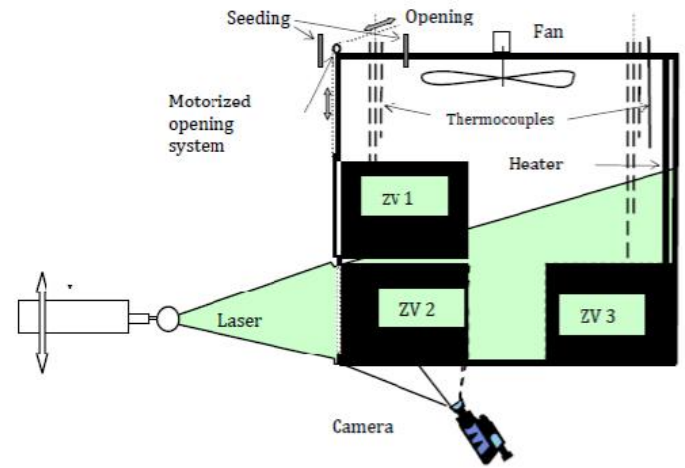

Fig. 6. Experimental setup for the characterization of the gravity wave $\mathrm{ZVi}$ are the PIV windows

PIV requires the seeding of flows with passive trackers (droplets or solid particles). An entertainment smoke generator (glycol water) is used to seed the cold inflow, a seeding system for Zirconium micro particles is used to seed inside the compartment where temperature is higher the boiling temperature of most liquids. From PIV results, mean and fluctuating velocity fields are determined.

\subsection{Main Results}

The rapid cold air entering the hot enclosure can induce, in the real conditions, a re-ignition of the available gaseous fuel; consequently, a dangerous flame can propagate through the compartment. This experimental study is conducted in post-flashover simulation conditions where the enclosure is electrically heated. It is aimed to a better knowledge of the flow mixing phenomena involved in the first period of a backdraft, before re-ignition in an enclosure (Guigay et al. 2009, 2010).

The aerodynamics mechanisms of thermal instabilities leading to the formation, and the propagation, of a gravity wave appearing when dense fresh air enters the hot enclosure are described. The results obtained are essential for calibration and validation of hydrodynamics and turbulent models used by physical models in safety analysis numerical tools. The applicative result is the determination of the more efficient mixing zone where the mixture reaches the flammability limit necessary for ignition.

Figures 7 show the evolution of the gravity wave when the opening is in middle opening configuration. Figures $7 \mathrm{a}$ and $7 \mathrm{~b}$ show that the inflow occupies, immediately after the door opening, the greatest sector of the opening and moves at a speed of $0,9 \mathrm{~m} / \mathrm{s}$. The wave is accelerated between ZV2 and ZV3 (Fig. 7c) to reach $1 \mathrm{~m} / \mathrm{s}$ on a wider surface with a strong entrainment of the hot fluid and a gas recirculation at the rear of the enclosure. The temporal follow-up of the phenomenon shows a pulsation in intensity of this wave.
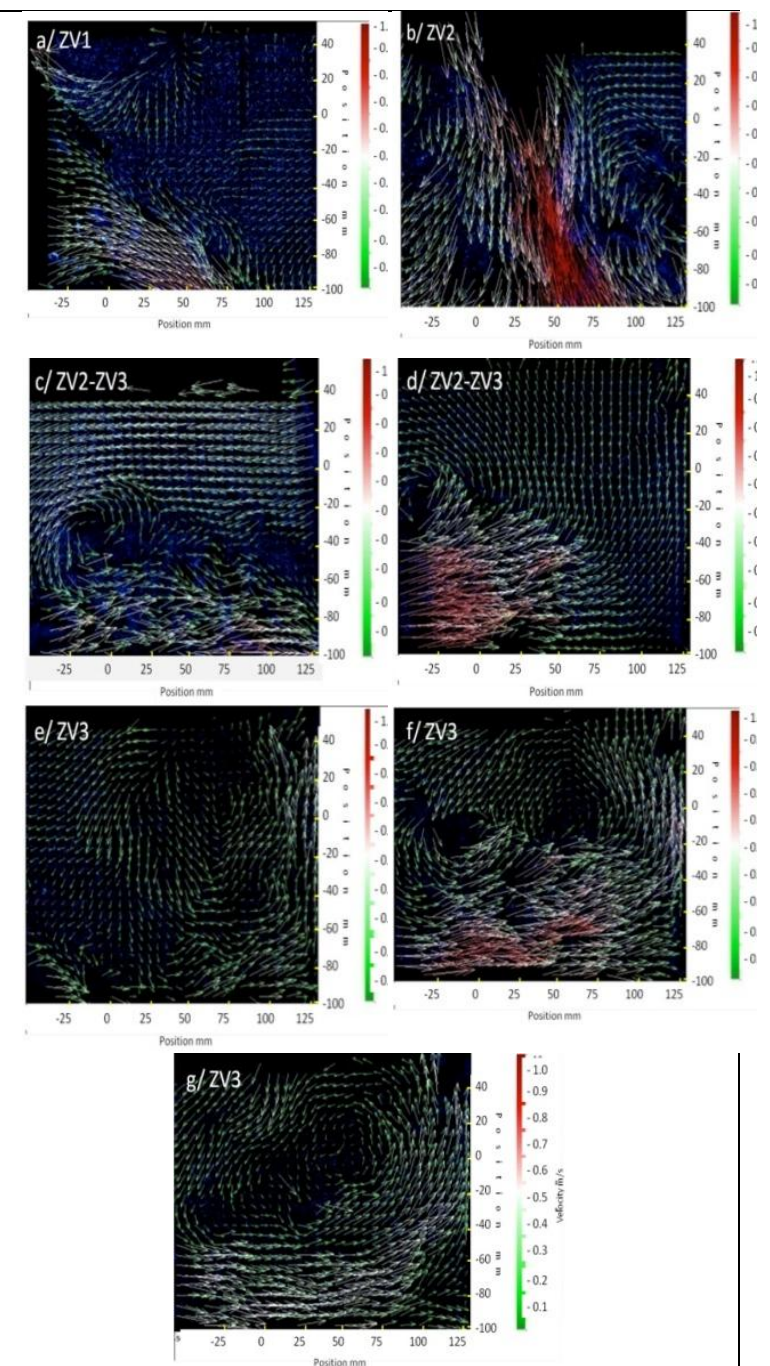

Figs. 7. Evolution of the instantaneous velocity fields during the displacement of the gravity wave. Door at the floor level

Figure $7 \mathrm{c}$ visualizes the propagation of a vortex structure with a thickness of about $0.1 \mathrm{~m}$ with a high shearing stress level.

Before the impact of the first structure on the wall (velocity $\sim 1 \mathrm{~m} / \mathrm{s}$ ), the hot fluid flow remains well organized (Figure $7 \mathrm{~d}$ represents the flow at the half distance from the rear). After the impact on the vertical back wall and before the arrival of the next structure (Fig. 7e), a disordered movement of the fluid is established with very fluctuating low speeds $(\sim 0,3 \mathrm{~m} / \mathrm{s})$. The mixing is not optimum. The next wave (Fig. 7f) has a speed reaching $0.8 \mathrm{~m} / \mathrm{s}$ and goes with large vortex structures. These movements support a more effective mixing for a longer length of time, in particular in the back corner of the enclosure. This turbulent mixture remains after the passage of the wave (Fig. $7 \mathrm{~g}$ ).

Tests are also performed with the bottom-opening door (Fig. 8). The comparison of the results shows a more limited mixing of the fluids which stay organised and relatively stratified. Without the fall of the gravity wave, the kinetic energy is located at the fluid interface, 
which reduces the entrainment of the external fluid towards the structure and decreases the risk to obtain an efficient mixing, which, in a real case, is likely to ignite.
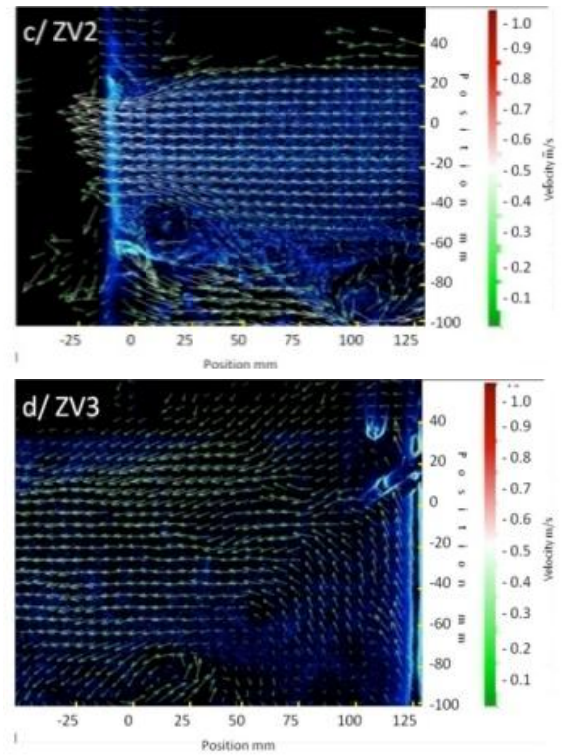

Fig. 8. Instantaneous velocity fields during the displacement of the gravity wave. Door at the floor level

The delay between the beginning of the door opening and the arrival of the gravity wave in the rear of the compartment has been also determined (Fig. 9). It decreases with the increase of the temperature difference and is smaller for the opening in the bottom position where it can be noted that the wave reaches the rear wall before the complete opening of the door (time of the complete opening: 1,08s). Nevertheless, the mixing is more efficient when the gravity wave penetrates through the middle opening.

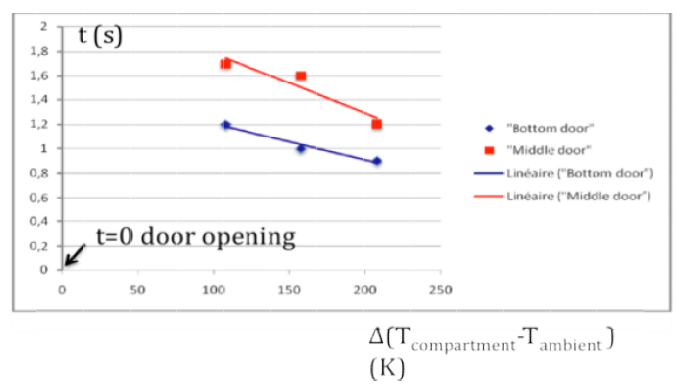

Fig. 9. Time of penetration of the gravity wave up to the rear of the compartment.

Consequently, it can be suggested that, though the mean wave velocity is slower for a middle opening, the pulsation of the flow increases the fluid mixing and induces a more dangerous phenomenon with a greater probability of backdraft.

\section{General Conclusion}

In this work, a complete post-flashover scenario for underventilated wall fire configurations have been performed in the same laboratory scale enclosure. In the first part of the study, the formation of a ghosting flame moving through the compartment is visualised as soon as the wall fire becomes strongly underventilated: no air entering leading to potential backdraft was observed. Experimental results indicate that the structure of the ghosting flame is closer to a diffusion flame than a premixed one, and despite a high fuel concentration in the enclosure, no backdraft was observed. The second part clearly shows the development of a gravity wave and the great influence of its fall, hence the influence of the position of the opening on the transport and mixing of the fluid, which reduces the potential time to ignition.

These fire behaviours are presently under numerical modelling to introduce the ghosting flame and backdraft phenomena into numerical safety analysis tools.

\section{REFERENCES}

Audouin, L., J.M. Such, J.C. Malet and C. Casselman (1997). A real scenario for a ghosting flame. Fifth International Symposium on Fire Safety Science, Melbourne, 1261-1272.

Babrauskas, V. and S.J. Grayson (1992). Heat Release in Fires. Elsevier Applied Science, London.

Bengtsson, L.G. and B. Karlsson (2000). An Experimental and Statistical Study of the phenomena Flashover, Backdraft and Smoke Gas Explosion. Presented at the 3rd International Seminar on Fire and Explosion Hazards.

Bertin, G., J.M. Most and Coutin (2002). Wall fire behaviour in an under-ventilated room. Fire Safety Journal.

Chitty, R. (1994). A Survey on Backdraught. Fire Research Station, Pub No 5/94.

Drysdale, D. (1999). An Introduction to Fire Dynamics. John Wiley and Sons, $2^{\text {nd }}$ Edition, New York.

Elíasson, J., G. Georges ande B. Karlsson (2008). Enclosure Fires, Gravity Waves, and the Backdraft Problem. Journal of Fire Sciences 26, 373- 397.

Fahy, R.F., P.R. LeBlanc (2006). Fire-Fighters Fatalities in the United States - 2005. Fire Analysis and Research Division, National Fire Protection Association.

Fleischmann, C.M. (1993). Backdraft Phenomena. University of California, Berkley.

Fleischmann, M. and K.B. McGrattan (1999). Numerical and Experimental Gravity Currents Related to Backdrafts. Fire Safety Journal 33, 2134.

Gojkovic, D. (2001). Initial Backdraft Experiments. Report 3121, Department of Fire Safety Engineering, Lund University, Sweden.

Gottuk, D.T., M.J. Peatross, J.P. Farley and F.W. Williams (1999). The development and mitigation 
J.M. Most and J.B. Saulnier / JAFM, Vol. 4, No. 2, Issue 1, pp. 129-135, 2011.

of backdraft: a real-scale shipboard study. Fire Safety Journal 33, 261-282.

Gross, D. and A.F. Robertson (1964). Experimental fires in enclosures. $10^{\text {th }}$ Symposium International on Combustion, Cambridge, Angleterre, 931-942.

Guigay, G. (2008). A CFD and Experimental Investigations of under Ventilated Compartment Fire. PhD Thesis, Faculty of Engineering, Univ. of Iceland.

Guigay, G., B. Karlsson and J. Elíasson (2006). Numerical and analytical determination of combustion products in strongly underventilated fires prior to backdraft. Presented in Workshop in Enclosure Fires, FIREsert.

Guigay, G., J.M. Most, F. Penot, A. Claverie, J. Eliasson and B. Karlsson (2009, June). The influence of thermal instabilities on the initial conditions of the backdraft phenomenon. $6^{\text {th }} \mathrm{MCS}$, Porticcio-Ajaccio, Corsica, France.

Guigay, G., J.M. Most, F. Penot, A. Claverie, J. Eliasson and B. Karlsson (2010). The influence of thermal instabilities on the initial conditions of the backdraft phenomenon, accepted for publishing in Fire Safety Journal.

Karlsson, B. and J.G. Quintiere (2000). Enclosure Fire Dynamics. CRC Press, Boca Raton.

Kawagoe, K. (1958). Fire Behavior in Rooms. Building Research Institute, Report $\mathrm{n}^{\circ} 27$, Ministry of Construction, Tokyo, Japan.

Morehart, J.H., E.E. Zukoski, T. Kubota (1992). Characteristics of large diffusion flames burning in a vitiated atmosphere. Fire Safety Science, Proceedings of the third international symposium, 575-583.

Pearson, A., J.M. Most and D. Drysdale (2007). Behaviour of a confined fire located in an underventilated zone. Proceedings of the Combustion Institute 31, 2529-2536.

Pedersen, F.B. (1986). Environmental Hydraulics: Stratified Flows. Springer Verlag Editions.

Penot, F. (1982). Numerical calculation of twodimensional natural convection in isothermal open cavities. Numerical Heat Transfer 5, 421-435.

Quintiere, J.G., B.J. McCaffrey and K. Den Braven (1978). Experimental and theoretical analysis of quasi-steady small-scale enclosure fires. Proceedings of $17^{\text {th }}$ Symposium Int. on Combustion, Leeds, Angleterre, 1125-1137.

Sugawa, O., K. Kawagoe, Y. Oka and I. Ogahara (1989). Burning behavior in a poorly ventilated compartment fire - Ghosting Fire. Fire Science \& Technology 9-2, 5-14.
Thomas, P.H. (1980/81). Fires and Flashover in rooms a simplified theory. Fire Safety Journal 3, 67-76.

Weng, W.G. and W.C. (2002). Fan Experimental Study of Backdraft in a Compartment with Different Opening Geometries and its Mitigation with Water Mist. Journal of Fire Sciences 20. 